\title{
Efeito da Adição de Material Vegetal (Fibra da Castanha de Cutia) e Polímero (SBS) nas Propriedades do Ligante Asfáltico (CAP 50/70)
}

\author{
Tayana M. F. Cunha, José C. Correia, Consuelo A. Frota \\ Departamento de Geotecnia, UFAM \\ Satomi M. Chaar, Paulo R. C. Couceiro \\ Departamento de Química, UFAM
}

\begin{abstract}
Resumo: Tendo em vista a necessidade do mercado brasileiro por ligantes que minimizem a prematura falência estrutural dos revestimentos nas vias urbanas, a modificação do cimento asfáltico de petróleo (CAP 50/70) constitui uma excelente opção tecnológica. Nesta pesquisa utilizou-se $2 \%$ p/p do copolímero de estireno-butadieno-estireno (SBS) e 2\% p/p de fibra natural da casca dos frutos de Couepia edulis (Prance), conhecida como castanha de cutia, material vegetal com característica de reforço e biodisponibilidade na região Amazônica. Os efeitos oxidativos e térmicos, bem como as características físicas dos materiais asfálticos modificados, foram estudados e comparados ao ligante convencional, utilizando-se ensaios estabelecidos pela Agência Nacional de Petróleo, Gás Natural e Biocombustíveis (ANP) e análise térmica - termogravimetria (TG), a fim de determinar as propriedades de degradação e estabilização térmica. Os resultados para os ligantes modificados, confrontados ao ligante tradicional, apresentaram: maior resistência ao envelhecimento, melhorias evidenciadas pelo aumento da consistência, ponto de amolecimento, além da excelente estabilidade térmica em toda faixa de temperatura de utilização $\left(10{ }^{\circ} \mathrm{C}\right.$ a $\left.80^{\circ} \mathrm{C}\right)$ e aplicação $\left(130^{\circ} \mathrm{C}\right.$ a $\left.170{ }^{\circ} \mathrm{C}\right)$ dos cimentos asfálticos de petróleo, fornecendo uma opção ao pavimento regional.
\end{abstract}

Palavras-chave: Copolímero SBS, fibras naturais, asfalto modificado, Amazonas, Couepia edulis, castanha de cutia.

\section{Effect of Addition of Plant Material (Fiber of Cutia Chesnut) and Polymer (SBS) on the Properties of Asphalt Binder (CAP 50/70)}

\begin{abstract}
There is a need in the Brazilian market for asphalt binders that minimize premature structural failure of the coatings on urban roads, and the modification of asphalt cement oil (CAP 50/70) is an excellent option. In this research we used $2 \%$ w/w of the styrene - butadiene-styrene (SBS) copolymer and 2\% w/w of natural fiber from Couepia edulis (Prance), known as cutia chesnut, which is a plant from the Amazon region with strengthening properties. The oxidative and thermal effects, as well as the physical characteristics of the asphalt modified materials, were studied and compared to the conventional binder, using the tests set by the National Agency of Petroleum, Natural Gas and Biofuels (ANP) and thermal analysis - thermogravimetry (TG) to determine the properties of thermal degradation and stabilization. In comparison with the traditional binders, the modified ones exhibited increased resistance to aging, evidenced by an increase in consistency, softening point and excellent thermal stability in the whole range of operating $\left(10{ }^{\circ} \mathrm{C}\right.$ to $80{ }^{\circ} \mathrm{C}$ ) and application $\left(130{ }^{\circ} \mathrm{C}\right.$ to $\left.170{ }^{\circ} \mathrm{C}\right)$ temperatures for the asphalt cement oil, providing an option for regional pavements.
\end{abstract}

Keywords: SBS copolymer, fibers, modified asphalt, Amazon, Couepia edulis, cutia chestnut.

\section{Introdução}

O cimento asfáltico de petróleo, distribuído pelas refinarias de petróleo, é fornecido ao mercado consumidor atendendo às características exigidas pela Agência Nacional de Petróleo, Gás Natural e Biocombustíveis (ANP) ${ }^{[1]}$. A incorporação de materiais poliméricos, ou ainda, com características de reforço ao asfalto, mostra-se como uma excelente alternativa na melhoria das suas propriedades físicas, químicas e reológicas, proporcionando uma maior durabilidade, resistência à deformação permanente e a mitigação do envelhecimento oxidativo durante a usinagem, aplicação e vida do ligante em serviço ${ }^{[2,3]}$.

Dentre os materiais utilizados na modificação de asfaltos, destacam-se os polímeros sintéticos, como o copolímero de estireno-butadieno-estireno (SBS), cuja adição ao cimento asfáltico de petróleo proporciona: maior coesão, aumento da elasticidade e/ou flexibilidade e da resistência ao envelhecimento e redução da susceptibilidade térmica, refletindo, assim, elevada resistência às deformações permanentes. Entretanto, é preciso salientar que altas concentrações de polímero são inviáveis economicamente, e segundo a literatura, menores concentrações podem garantir efeitos positivos aos ligantes asfálticos ${ }^{[4-6]}$.
Neste contexto, o trabalho em pauta demonstra inovação quando busca materiais oriundos de fontes naturais - passivos ambientais resultantes do uso das matérias-primas provenientes das terras, águas e florestas na Amazônia brasileira, visando a melhoria dos cimentos asfálticos de petróleo partícipe dos compostos asfálticos. Tais materiais se constituem em uma realidade na produção e reprodução do modo de vida dos grupos sociais habitantes dessa região e, portanto, o incentivo ao uso sustentado desses recursos, proporcionará o desenvolvimento de práticas economicamente sustentáveis, socialmente justas e ambientalmente corretas ${ }^{[7]}$.

Para tanto, tem-se a abundância de espécies vegetais presentes na biodiversidade Amazônica com grande potencial de utilização, porquanto produzem sementes oleaginosas e crescem espontaneamente no imenso território que forma a bacia do rio Amazonas. No caso da Couepia edulis (Prance), as suas cascas não recebem reaproveitamento durante a extração das amêndoas desse fruto, sendo seus resíduos simplesmente descartados e, conseqüentemente, um passivo ambiental, porém, com potencial aplicação como material de reforço, por se tratar de fibras duras com ótimo índice de rigidez ${ }^{[8]}$. 
A espécie Couepia edulis, conhecida como castanha de cutia, pertence à família Chrysobalanaceae, possui amêndoa de cor branca e apresenta casca fibrosa, densa, lisa e muito rígida ${ }^{[9]}$, com potencialidade de ser empregada, seja como matéria-prima para a queima na produção de carvão vegetal, ou para uso como aditivo de reforço em materiais estruturais, assim como material prensado na fabricação de móveis, entre outros ${ }^{[8]}$. Atendendo, neste caso, ao binômio economia versus meio ambiente, visto que seu uso terá impacto na redução da dependência de materiais provenientes de fontes não-renováveis (fósseis) ${ }^{[10,11]}$.

Nesta pesquisa, a utilização de fibras naturais teve como motivação melhorar diretamente as propriedades do cimento asfáltico de petróleo atuando como agente de reforço, por exemplo, elevando a sua viscosidade, bem como na durabilidade dos compósitos onde participarão - objeto de futuros trabalhos. No entanto, os efeitos desejados dependerão do tipo (forma, tamanho, superfície de contato), concentração e temperatura de adição ao ligante asfáltico ${ }^{[12-14]}$.

Avaliou-se no presente trabalho as modificações apresentadas pelo cimento asfáltico de petróleo empregado regionalmente (CAP50/70), pela incorporação da fibra da Couepia edulis (Prance) e do copolímero de estireno-butadieno-estireno (SBS), objetivando melhorar as suas propriedades reológicas e, assim, contribuir para um melhor desempenho mecânico do citado material e dos compósitos asfálticos em temperaturas elevadas, proporcionando maior durabilidade aos pavimentos regionais.

\section{Parte Experimental}

\section{Materiais}

Na presente pesquisa utilizaram-se três materiais, quais sejam: o ligante asfáltico de petróleo, o copolímero SBS e a regionalmente denominada fibra da castanha de cutia.

O cimento asfáltico de petróleo (CAP50/70) utilizado foi produzido e cedido pela Refinaria Isaac Sabbá (REMAN), da empresa Petróleo Brasileiro S.A (Petrobras), por meio da mistura de petróleos oriundos do Campo Fazenda Alegre (CAPFA), situado no estado do Espírito Santo, e Ceará- Mar, proveniente do estado do Ceará. O copolímero de estireno e butadieno (SBS), fornecido pelo Centro de Pesquisas da Petrobras (CENPES), apresenta as características constantes na Tabela 1. Estudos referenciam que o uso desse polímero, com características de elastômeros termoplásticos, atua de forma satisfatória nas propriedades físicas e mecânicas dos materiais asfálticos ${ }^{[4-6,15-17]}$, tais como: o acréscimo no retorno elástico e a melhoria da resistência à deformação permanente por alongamento e recuperação.

Por outro lado, os frutos da Couepia edulis (Prance) foram coletados na comunidade do Roque, localizada na reserva extrativista do médio Juruá, no estado do Amazonas (Figura 1), onde está instalada uma usina piloto de extração de óleos de frutos

Tabela 1. Caracterísitcas do polímero SBS.

\begin{tabular}{ccccc}
\hline Amostra & $\begin{array}{c}\text { Estireno } \\
\text { \%p }\end{array}$ & $\begin{array}{c}\text { Butadieno } \\
\mathbf{1 , 2} \% \mathbf{p}\end{array}$ & $\begin{array}{c}\text { Butadieno } \\
\text { (cist+4 } \\
\text { (c) p }\end{array}$ & $\begin{array}{c}\text { Butadieno } \\
\text { total \%p }\end{array}$ \\
\hline SHELL & $3,4 \times 10^{1}$ & $6,0 \times 1$ & $6,0 \times 10^{1}$ & $6,6 \times 10^{1}$ \\
TR 1101 & \multicolumn{4}{c}{ Peso molecular } \\
grânulos & $\mathrm{M}_{\mathrm{n}}$ & $\mathrm{M}_{\mathrm{w}}$ & $\mathrm{M}_{\mathrm{z}}$ & Polidispersão \\
& $1,1 \times 10^{5}$ & $1,4 \times 10^{2}$ & $1,7 \times 10^{2}$ & $1,3 \times 1$ \\
\hline
\end{tabular}

Mn - massa molar numérica; Mw - massa molar ponderal; Mz - massa molar média. de oleaginosas amazônicas, de forma mecanizada, conciliando o desenvolvimento sustentável e a preservação da floresta em relação à utilização dos resíduos gerados - cascas do fruto Couepia edulis (Prance), aumentando, destarte, a introdução no mercado de novos produtos oriundos de fontes naturais ${ }^{[18]}$.

A obtenção das fibras da Couepia edulis (Prance) consistiu inicialmente da separação da amêndoa da casca por prensagem, seguida de trituração, em moinho de facas, das cascas dos frutos (Figura 2). Em seguida, ajustou-se a granulometria deste material próxima à do polímero SBS. Para tanto, realizou-se ensaio de peneiramento e separou-se o material retido na peneira $\# 0,297 \mathrm{~mm}$, utilizado na mistura, cuja distribuição granulométrica está apresentada na Figura 3c.

Não se realizou um pré-tratamento da fibra, todavia, durante os experimentos, observou-se a sua necessidade e, igualmente, a medição da dispersão, visto que apresentou sedimentação na mistura com o ligante asfáltico.

\section{Métodos}

Inicialmente definiram-se em $2 \% \mathrm{p} / \mathrm{p}$ o percentual de SBS e fibra vegetal para a modificação do CAP 50/70, com o intuito de minimizar os custos do produto final e, ainda, verificar a influência de baixas concentrações de modificadores em ligantes asfálticos.

No processo de modificação do material asfáltico utilizou-se um misturador, modelo Fisaton 647, composto de agitador mecânico com hélice cisalhante, sonda, controlador de temperatura, bécker de vidro com capacidade de $5 \mathrm{~L}$ e manta aquecedora, marca Solotest. $\mathrm{Na}$ preparação das misturas, aqueceu-se o ligante à temperatura de $80^{\circ} \mathrm{C}$, a fim de facilitar a adição dos modificadores, transferindo-o em seguida para o misturador, obedecendo às seguintes condições: rotação de $300 \mathrm{rpm}$ por 2 horas, sob aquecimento a $150 \pm 5^{\circ} \mathrm{C}^{[4]}$. Realizaram-se os experimentos em triplicata e seus resultados foram apresentados como a média dos mesmos.

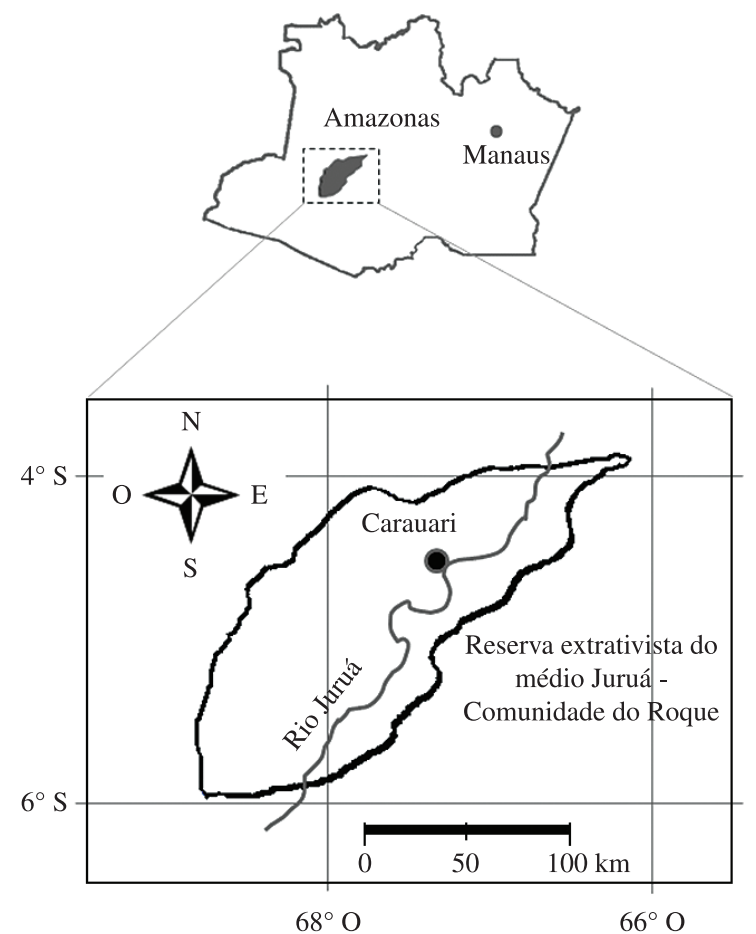

Figura 1. Localização geográfica da coleta da castanha de cutia (Couepia edulis Prance). 


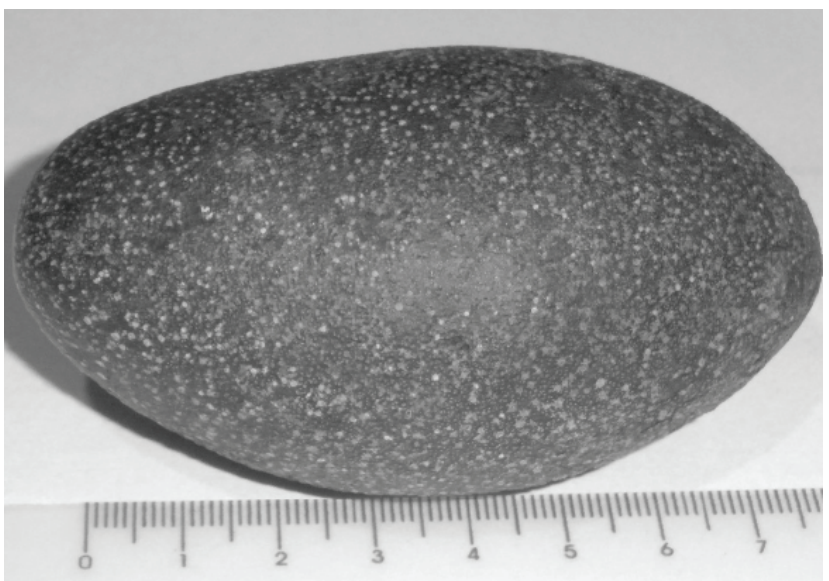

(a)

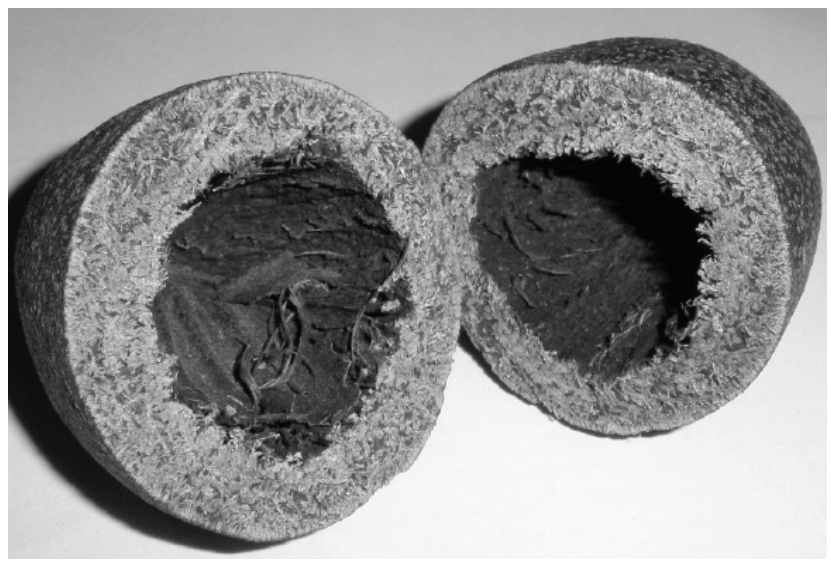

(c)

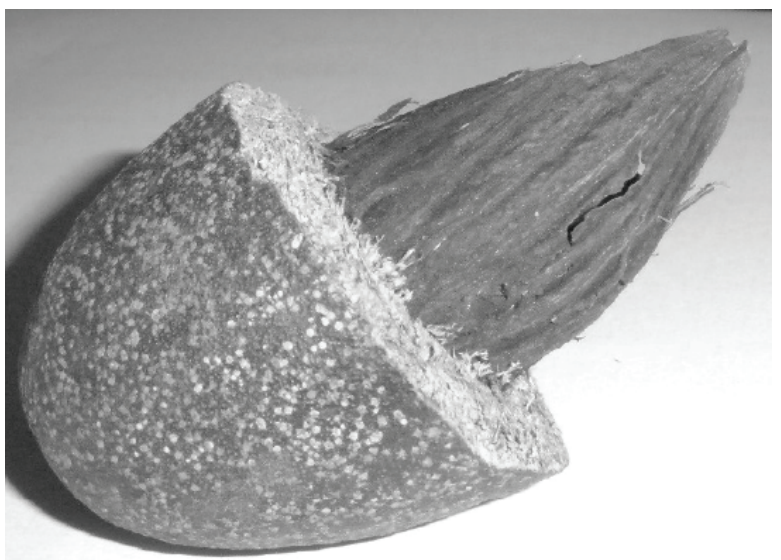

(b)

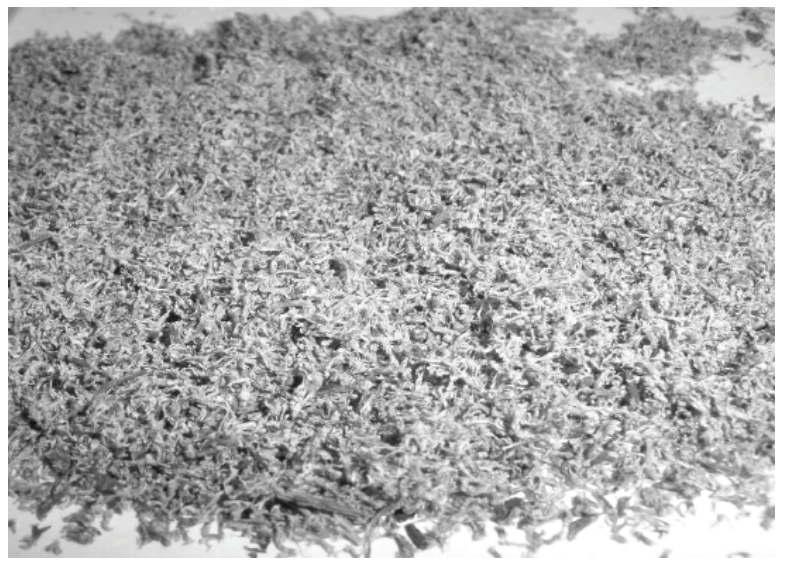

(d)

Figura 2. a) Fruto Couepia edulis Prance (castanha de cutia), b) Corte transversal do fruto, c) Cascas do fruto e d) Casca do fruto triturada (fibra).

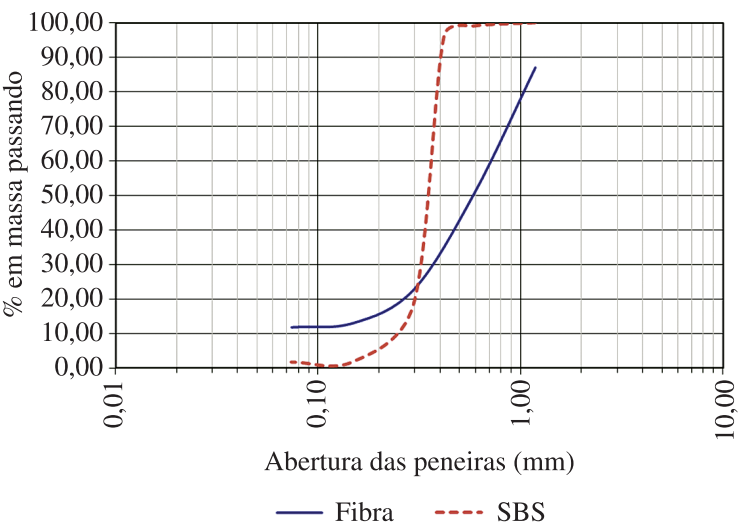

Figura 3. Distribuição granulométrica da fibra da castanha de cutia e do polímero SBS.

Os dois ligantes asfálticos modificados foram preparados a partir da mistura do material asfáltico (CAP 50/70), comercializado em Manaus, com 2\% de massa do copolímero de estireno-butadieno-estireno (SBS), denominado de LM2\%SBS, e com as fibras das cascas do fruto Couepia edulis (LM2\%FCC), respectivamente. Submeteu-se a amostra LM2\%SBS à agitação mecânica de $300 \mathrm{rpm}$, por 2 horas em temperatura controlada de $150 \pm 5{ }^{\circ} \mathrm{C}^{[6]}$. Enquanto a amostra LM2\%FCC foi agitada mecanicamente na condição de $560 \mathrm{rpm}$, durante 2 horas, e sob temperatura de $160 \pm 5{ }^{\circ} \mathrm{C}^{[19]}$. Salienta-se que tais condições basearam-se na revisão bibliográfica relativa a outros tipos de fibras, uma vez que não se tem registro da utilização da castanha de cutia como modificador de ligantes asfálticos ${ }^{[17,19,20,22-25]}$. Preliminarmente realizaram-se os ensaios estabelecidos pela $\mathrm{ANP}^{[1]}$ e, posteriormente, os experimentos concernentes à análise térmica (TG) para os ligantes puros (CAP 50/70) e modificados (LM2\%SBS e LM2\%FCC).

Realizou-se o ensaio de envelhecimento em estufa em película delgada rolada (RTFOT), segundo a norma ASTM D2872[26]. Neste, o envelhecimento da amostra asfáltica ocorre por oxidação e evaporação, utilizando um equipamento RTFOT, modelo ISL, sob a temperatura de $163 \pm 5^{\circ} \mathrm{C}$ por 85 minutos e vazão barométrica igual a $4200 \pm 200 \mathrm{~mL} / \mathrm{min}$ de ar sintético.

O teste de penetração (ASTM D5) ${ }^{[27]}$, selecionado para avaliar a consistência do ligante, foi realizado em um penetrômetro Setamatic, com temperatura de $25 \pm 1{ }^{\circ} \mathrm{C}$, massa de $100 \mathrm{~g}$, por 5 segundos de duração. Determinou-se o ponto de amolecimento objetivando-se correlacionar a condição de escoamento e a consistência relativa dos asfaltos, conforme ASTM D36 $6^{[28]}$, em um equipamento "softening point tester" HRB-754, da Herzog, utilizando esferas de aço de 9,5 mm de diâmetro e massa dos ligantes 3,50 $\pm 0,05 \mathrm{~g}$.

Examinou-se a ductilidade dos ligantes modificados (ASTM D113) ${ }^{[29]}$ em um ductilômetro Lactea Julabo, modelo PC, na temperatura de $25 \pm 1^{\circ} \mathrm{C}$ e velocidade de $5 \mathrm{~cm} / \mathrm{min}$, a fim de verificar as propriedades elásticas dos materiais e sua capacidade em suportar grandes deformações, além da coesão e resistência dos cimentos asfálticos quando submetidos à tração até o ponto de ruptura. 
Para o ensaio de densidade empregou-se o método do picnômetro (ASTM D70) $)^{[30]}$, na temperatura de $25{ }^{\circ} \mathrm{C} / 4{ }^{\circ} \mathrm{C}$, e no caso das

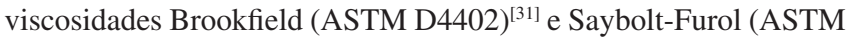
E102) ${ }^{[32]}$, foram usados os viscosímetros Brookfield, modelo RV DVIII Ultra, e Koehler, modelo K21424, respectivamente, nas temperaturas de 135,150 e $177^{\circ} \mathrm{C}$.

A medida do ponto de fulgor (ASTM D92) ${ }^{[33]}$ foi realizada em um equipamento Cleveland ISL, modelo FP92 - 5 G2, na taxa de $2{ }^{\circ} \mathrm{C}$. Verificou-se, igualmente, a solubilidade dos ligantes em tricloroetileno, $\mathrm{C}_{2} \mathrm{HCl}_{3}$, (ASTM D2042) ${ }^{[34]}$ - indicativo da atividade dos constituintes no ligante, estabelecendo, por conseguinte, as impurezas presentes nos materiais asfálticos, pelo método gravimétrico utilizando cadinho Gooch.

A análise termogravimétrica (TG) foi realizada em um termoanalisador TG/DTA simultâneo, modelo DTG-60H, sendo aquecidas continuamente em torno de $10 \mathrm{mg}$ de cada amostra, na taxa de $10{ }^{\circ} \mathrm{C} / \mathrm{min}$, faixa de temperatura de 25 a $700{ }^{\circ} \mathrm{C}$, e sob fluxo de nitrogênio $\left(\mathrm{N}_{2}\right)$.

\section{Resultados e Discussão}

A principal função das fibras adicionadas ao asfalto é melhorar o desempenho do asfalto, notadamente em altas temperaturas - caso da região amazônica, gerando reforço ao revestimento. Porém, tal comportamento depende do tipo e do teor de fibras, uma vez que se tem a formação de uma rede tridimensional que engrossa o filme e a estrutura do asfalto ${ }^{[19]}$. Neste trabalho a aplicação das fibras da casca do fruto da Couepia edulis (Prance) fundamenta-se, principalmente, no rendimento de $71 \% \mathrm{~m} / \mathrm{m}$ e nos valores de lignina, variando de 30 a $35 \% \mathrm{~m} / \mathrm{m}$, registrados por Pessoa e colaboradores ${ }^{[8]}$. Esses valores de lignina são superiores aos do sisal ${ }^{[20]}(7$ a $11 \%)$ e da juta (15\%), mas inferiores ao da fibra do coco $(35 \text { a } 45 \%)^{[21,22]}$, podendo conferir uma maior resistência ao comportamento mecânico quando incorporadas aos compósitos asfálticos - objeto da continuação do estudo em pauta.

Os ligantes modificados, LM2\%SBS e LM2\%FCC, tiveram incorporação limite de $2 \%$ de polímero e fibras visando não elevar o custo e também não aumentar excessivamente a viscosidade, o que poderia atribuir características não favoráveis para o revestimento asfáltico. Porquanto, nos compósitos asfálticos as fibras são adicionadas, em geral, em misturas do tipo SMA (Stone Matrix Asphalt) visando evitar o escorrimento do cimento asfáltico de petróleo durante a produção, o transporte e a aplicação em campo. Tais materiais geram uma película mais espessa ao redor do agregado, respeitante a outros tipos de misturas, retardando a oxidação, a penetração de umidade e a separação dos agregados, aumentando a resistência ao desgaste do concreto asfáltico produzido ${ }^{[23]}$.

Os resultados dos ensaios estabelecidos pela $\mathrm{ANP}^{[1]} \mathrm{e}$ concernentes aos ligantes avaliados, puro (CAP50/70) e modificados (LM2\%SBS e LM2\%FCC), são apresentados na Tabela 2. O CAP50/70, material certificado pela REMAN, e tomado como referência para este estudo, mostrou estar em conformidade com as especificações técnicas.

Atinente aos ligantes modificados, observou-se desvios das especificações nos parâmetros ductilidade, viscosidades Brookfield e Saybolt-Furol e, particularmente, para o ligante LM2\%FCC relativo ao ponto de amolecimento depois do ensaio de envelhecimento oxidativo em estufa de película delgada rolada (RFTOT). O ensaio de ductilidade, quando resulta em redução dos valores, pode levar à ruptura por tração do material betuminoso ${ }^{[35]}$. Tais valores a $25{ }^{\circ} \mathrm{C}$, antes e após ao ensaio RTFOT, para o LM2\%SBS e o LM2\%FCC, foram bastante inferiores aos especificados (Tabela 2). No caso do ligante LM2\%SBS, a variação de ductilidade ficou em torno de $31 \mathrm{~cm}$, enquanto o LM2\%FCC mostrou uma variação de aproximadamente $10 \mathrm{~cm}$, valor menor do que a variação especificada $(40 \mathrm{~cm})$ antes e após o ensaio RTFOT.

Nos resultados alusivos aos ensaios das viscosidades Brookfield e Saybolt-Furol observa-se que os valores obtidos para os ligantes modificados com polímero e fibra (LM2\%SBS e LM2\%FCC, respectivamente) foram superiores aos valores do material asfáltico puro (CAP50/70). Essa característica dos asfaltos modificados induzirá a formação de uma película de cimento asfáltico mais espessa sobre os agregados, contribuindo, de tal modo, para a

Tabela 2. Especificações técnicas para o CAP 50/70 (ANP - Resolução $\left.n^{\circ} 19 / 2005\right)^{[1]}$ e resultados dos ensaios para o CAP50/70 e para os ligantes modificados (LM2\%SBS e LM2\%FCC).

\begin{tabular}{|c|c|c|c|c|}
\hline Característica & Especificação & CAP5070(1) & LM2\%SBS & LM2\%FCC \\
\hline aquecimento, $177^{\circ} \mathrm{C}$, NA & NESP & NESP & NESP & NESP \\
\hline densidade relativa, $25^{\circ} \mathrm{C}, \mathrm{NA}$ & Anotar & 0,998 & $0,994 \pm 0,002$ & $0,971 \pm 0,004$ \\
\hline ductilidade, $25^{\circ} \mathrm{C}$ (a), cm & 60 mín & $>100$ & $41,5 \pm 0,2$ & $27,3 \pm 0,3$ \\
\hline ductilidade, $25^{\circ} \mathrm{C}(\mathrm{d}), \mathrm{cm}$ & 20 mín & 42 & $10,5 \pm 0,2$ & $17,6 \pm 0,3$ \\
\hline penetração, $0,1 \mathrm{~mm}$ & 50 a 70 & 69 & $55 \pm 1$ & $52 \pm 1$ \\
\hline ponto de amolecimento (a), ${ }^{\circ} \mathrm{C}$ & 46 mín & 49,7 & $52,5 \pm 0,2$ & $50,9 \pm 0,1$ \\
\hline $\begin{array}{l}\text { aumento do ponto de } \\
\text { amolecimento }(\mathrm{d}),{ }^{\circ} \mathrm{C}\end{array}$ & 8 máx & 7,1 & $9,3 \pm 0,1$ & $6,7 \pm 0,3$ \\
\hline ponto de fulgor, ${ }^{\circ} \mathrm{C}$ & 235 mín & 318 & $324 \pm 3$ & $306 \pm 4$ \\
\hline penetração retida ${ }^{(\mathrm{d})}, \%$ & 55 mín & 63 & $69 \pm 1$ & $63 \pm 1$ \\
\hline variação em massa ${ }^{(\mathrm{d})}, \%$ & 0,5 máx & 0,04 & $0,075 \pm 0,006$ & $0,081 \pm 0,004$ \\
\hline solubilidade $\mathrm{em} \mathrm{C}_{2} \mathrm{HCl}_{3}, \%$ & 99,5 mín & 99,9 & $99,7 \pm 0,2$ & $98,8 \pm 0,1$ \\
\hline visc. Brookfield, $135^{\circ} \mathrm{C}, \mathrm{cp}$ & 274 mín & 539 & $1890,2 \pm 0,2$ & $2186,5 \pm 0,3$ \\
\hline visc. Brookfield, $150^{\circ} \mathrm{C}, \mathrm{cp}$ & 112 mín & 271 & $827,3 \pm 0,1$ & $835,8 \pm 0,4$ \\
\hline visc. Brookfield, $177^{\circ} \mathrm{C}, \mathrm{cp}$ & 57 a 285 & 97 & $295,5 \pm 0,5$ & $297,4 \pm 0,1$ \\
\hline visc. Saybolt-Furol, $135^{\circ} \mathrm{C}, \mathrm{s}$ & 141 mín & 283 & $301 \pm 6$ & $394 \pm 4$ \\
\hline visc. Saybolt-Furol, $150^{\circ} \mathrm{C}, \mathrm{s}$ & 50 mín & 141 & $149 \pm 3$ & $181 \pm 5$ \\
\hline visc. Saybolt-Furol, $177^{\circ} \mathrm{C}, \mathrm{s}$ & 30 a 150 & 51 & $57 \pm 2$ & $79 \pm 3$ \\
\hline
\end{tabular}

ASTM - American Standard Test Method; (1) - valores certificados pela refinaria; (a) - antes do ensaio em estufa de película delgada rolada (RTFOT); (d) - pois do ensaio de envelhecimento oxidativo em estufa de película delgada rolada (RTFOT); NESP - Não Espuma; NA - Não Aplicável; visc. - viscosidade; mín - mínimo; máx - máximo 
durabilidade dos compósitos asfálticos, por melhoria da adesividade e da resistência ao envelhecimento das citadas misturas em campo ${ }^{[3]}$.

Particularmente, o ligante LM2\%FCC apresentou valores de viscosidades (Brookfield e Saybolt- Furol) elevados, quando comparado ao LM2\%SBS, em decorrência da distribuição das fibras no CAP50/70 ${ }^{[36]}$.

Para o aumento do ponto de amolecimento após o ensaio RTFOT, o LM2\%SBS apresentou valor superior ao especificado $\left(<8{ }^{\circ} \mathrm{C}\right)$. Segundo Oda $(2000)^{[36]}$, esse resultado deve-se à maior resistência à deformação permanente, por escoamento do ligante. Lima $(2008)^{[35]}$ reporta que pontos de amolecimentos elevados fornecem ao pavimento uma maior resistência as deformações permanente em dias quentes.

As variações em massa dos ligantes modificados (LM2\%SBS e LM2\%FCC), depois da análise em RTFOT, apresentaram acréscimo em comparação ao ligante puro, indicando a ocorrência de processo oxidativo das amostras natemperatura de ensaio $\left(160^{\circ} \mathrm{C}\right)$. Igualmente, quanto aos dados referentes à solubilidade em tricloroetileno, ponto de fulgor e densidade relativa a $25{ }^{\circ} \mathrm{C} / 4{ }^{\circ} \mathrm{C}$, constantes na Tabela 2 , tem-se que as amostras dos ligantes modificados (LM2\%SBS e LM2\%FCC) confrontadas ao CAP50/70, não mostraram variações significativas e, ao mesmo tempo, atenderam à especificação estabelecida pelo DNIT ${ }^{[37]}$, exceto para o resultado de solubilidade em tricloroetileno do ligante modificado (LM2\%FCC), decorrente da precipitação da fibra quando incorporada ao cimento asfáltico de petróleo.

A presença de fibras em CAPs fornece maior resistência a variações de temperaturas (altas e baixas) sem que haja uma grande degradação dos seus constituintes ${ }^{[38]}$. Entretanto, a adição de fibra não modifica quimicamente o ligante, mas eleva a consistência do material betuminoso, acarretando melhorias nas propriedades físicas do produto final, por admitir o uso de elevado teor de ligante de modo que não escorra do agregado antes da etapa de compactação $^{[39]}$

O valor da penetração para o ligante puro, igual a $69(0,1 \mathrm{~mm})$, ficou muito próximo do limite superior especificado. Para os ligantes modificados (LM2\%SBS e LM2\%FCC), a diminuição acentuada nos valores da penetração, comparados ao do CAP 50/70, é um indicativo do aumento da consistência desses materiais. Para o LM2\%FCC, também, observou-se redução dos valores da penetração antes e posterior ao RTFOT. Contudo, foram valores menos pronunciados em relação ao LM2\%SBS, possivelmente pela aderência do material betuminoso às superfícies das partículas da fibra e alteração na microestrutura das amostras.

Para o ponto de amolecimento, notou-se aumento para o LM2\%SBS e para o LM2\%FCC, quando confrontados ao ligante puro (CAP50/70). Esse acréscimo é um resultado positivo, visto que proporcionará maior resistência à deformação permanente das misturas asfálticas contendo ligante modificado ${ }^{[36]}$ - ganho ao principal problema apresentado pelos pavimentos da cidade de Manaus.

\section{Análise de Termogravimetria (TG)}

A Figura 4 mostra as curvas termogravimétricas do ligante CAP50/70, do polímero SBS, da fibra (FCC), e dos ligantes modificados (LM2\%SBS e LM2\%FCC), registradas na faixa de temperatura entre 25 a $700{ }^{\circ} \mathrm{C}$, em atmosfera inerte de $\mathrm{N}_{2}$.

A curva TG para o CAP50/70 mostrou perfil gráfico característico de apenas um evento térmico de decomposição, iniciando em $352{ }^{\circ} \mathrm{C}$ (limite de estabilidade térmica) e terminando em $492{ }^{\circ} \mathrm{C}$, referente a perda de massa de $78,1 \%$, típica de materiais orgânicos da classe de hidrocarbonetos de alto peso molecular. Conforme Mothé (2009) ${ }^{[25]}$ e Bringel (2007) ${ }^{[4]}$ tal comportamento caracteriza degradação dos maltenos e asfaltenos, respectivamente.

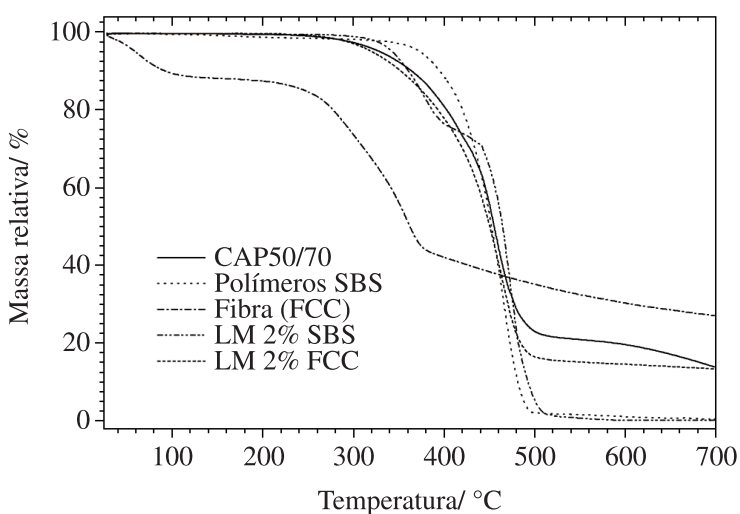

Figura 4. Curvas Termogravimétricas: CAP50/70 (Ligante), polímero SBS, fibra (FCC), e ligantes modificados. (LM2\%FCC e LM2\% SBS).

No que concerne ao polímero SBS, a curva TG em atmosfera inerte mostra um evento de decomposição para as temperaturas iguais a $403{ }^{\circ} \mathrm{C}$ e $486{ }^{\circ} \mathrm{C}$, inicial e final, respectivamente. $\mathrm{O}$ LM2\%SBS indica dois eventos de decomposição, sendo o primeiro entre as temperaturas de $332{ }^{\circ} \mathrm{C}$ (inicial) e $396{ }^{\circ} \mathrm{C}$ (final), com $22,1 \%$ de perda de massa, e o segundo, entre $444{ }^{\circ} \mathrm{C}$ e $506{ }^{\circ} \mathrm{C}$. Portanto, o polímero SBS apresentou uma boa resistência térmica, comprovando a sua utilização como matéria - prima adequada à mistura com o CAP50/70 para aplicação na construção de pavimentos.

O comportamento da curva TG para a FCC (Figura 4) apresentou três processos de perda de massa: a) inicialmente, até $100{ }^{\circ} \mathrm{C}$, com uma pequena variação de redução em torno de $11 \%$ em massa, típica de perda de umidade; b) na segunda, houve uma variação acentuada a partir de $255^{\circ} \mathrm{C}$, com perda de $43 \%$ da massa, atribuída à decomposição da hemicelulose e quebra de ligações da celulose; e c) a última etapa ocorreu a partir de $375^{\circ} \mathrm{C}$, devido a decomposição final da celulose e da lignina, com teor final de resíduos de $20 \%$. Esse comportamento foi semelhante ao observado por Martin et al. (2009) ${ }^{[22]}$, que considerou como um índice da estabilidade térmica do material a temperatura na qual $50 \%$ de decomposição da massa inicial é observada ${ }^{[22,40]}$. Para a amostra de FCC, observou-se que esta redução da massa inicial ocorreu em $360{ }^{\circ} \mathrm{C}$.

Para a amostra do LM2\%FCC, a curva TG se comportou analogamente a curva do CAP50/70, mostrando apenas um evento térmico de decomposição entre temperaturas de $305{ }^{\circ} \mathrm{C}$ e $490{ }^{\circ} \mathrm{C}$, inicial e final, respectivamente. Com relação ao teor de resíduo constatado ao final do ensaio, verificou-se que a amostra incorporada com a fibra resultou em aproximadamente $15 \%$.

O principal constituinte da fibra da castanha de cutia, com destacada importância para essa pesquisa foi, notadamente, a componente lignina, com cerca de $30 \%$ em massa, sendo responsável pela resistência estrutural das amostras modificadas. Nesse contexto, e como visto, a degradação térmica da lignina ocorreu lentamente a partir de $375^{\circ} \mathrm{C}$ e se prolongou até o valor de $700{ }^{\circ} \mathrm{C}$, afigurando-se a FCC como reforço ao cimento asfáltico de petróleo - objetivo maior do presente estudo.

\section{Conclusão}

Os ligantes modificados com fibra da castanha de cutia e com SBS não se enquadram nas especificações quanto à ductilidade, viscosidades Brookfield e Saybolt-Furol, e, particularmente, para o ligante LM2\%FCC, em relação ao ponto de amolecimento depois do ensaio RTFOT. Esses resultados, aparentemente negativos em comparação com as especificações do cimento asfáltico de petróleo puro (CAP50/70), não inviabilizam sua utilização em pavimentação 
na região Amazônica, especificamente em Manaus/AM, pois garantem adequabilidade às condições típicas de clima quente e úmido.

Por outro lado, as demais especificações para os ligantes modificados não apresentaram mudanças significativas. Porém, evidenciaram alterações positivas quanto à resistência a deformação permanente, sendo, consequientemente materiais que representam uma excelente alternativa para uso nos pavimentos da capital do estado do Amazonas.

A análise termogravimétrica dos ligantes (CAP50/70, $\mathrm{LM} 2 \% \mathrm{SBS}$ e LM2\%FCC) corroborou as observações anteriores, pois confirmou que esses materiais apresentam excelente estabilidade térmica quando submetidos a temperaturas em torno dos $300{ }^{\circ} \mathrm{C}$, o que garante o uso desses materiais em condições agressivas e altas temperaturas.

\section{Agradecimentos}

Ao Dr. Sergio Massayoshi Nunomura do Centro de Pesquisas em Produtos Naturais (CPPN), do Instituto Nacional de Pesquisas da Amazônia - INPA, pela valiosa colaboração no procedimento para obtenção das fibras da casca de castanha de cutia.

Ao Prof. Dr. Jamal da Silva Chaar, coordenador do Laboratório de Pesquisas e Análises de Combustíveis (LAPEC), da Universidade Federal do Amazonas (UFAM), pelas análises termogravimétricas.

Ao Laboratório de Otimização/Desenvolvimento de Produtos (OT/DP), da Refinaria de Manaus (REMAN), pelas análises de especificações dos ligantes asfálticos objeto de estudo desse trabalho.

\section{Referências Bibliográficas}

1. Agência Nacional do Petróleo - ANP. Resolução ANP Nº 19, de 11 de julho de 2005. Regulamento técnico N³/2005. Agência Nacional do Petróleo. Diário Oficial da República Federativa do Brasil, 12 jul. (2005).

2. Morilha Junior, A. - "Estudo sobre a ação de modificadores no envelhecimento dos ligantes asfálticos e nas propriedades mecânicas $e$ de fadiga das misturas asfálticas”. Dissertação de Mestrado, Universidade Federal de Santa Catarina, Brasil (2004).

3. Morales, M. G.; Partal, P. \& Navarro, F. - J. Fuel, 83, p.31 (2004). http://dx.doi.org/10.1016/S0016-2361(03)00217-5

4. Bringel. R. M. - "Estudo químico e reológico de ligantes asfálticos modificados por polímeros e aditivos". Dissertação de Mestrado, Universidade Federal do Ceará, Brasil (2006).

5. Lucena, M. C. C.; Soares, S. A. \& Soares, J. B. - "Efeito da Adição de SBS nas Propriedades Químicas e Reológicas de Asfalto Oriundo de Petróleo Brasileiro", in: Resumos do $2^{\circ}$ Congresso Brasileiro de P\&D em Petróleo \& Gás, p.160, Rio de Janeiro, Brasil (2003).

6. Leite, L. F. M. - "Estudos de Preparo e Caracterização de Asfaltos Modificados por Polímeros", Tese de Doutorado, Universidade Federal do Rio de Janeiro, Brasil (1999).

7. Freitas, A. L. C. - "Design e Artesanato "Uma experiência de inserção da metodologia de projeto de produto", Dissertação de Mestrado, Universidade Federal de Minas Gerais, Brasil (2006).

8. Pessoa, J. D. C.; Leeuwe, O. B. G. A.; Braz. D. C.; Gomes, J. I.; Silva, S. E. \& Kanno, S. S. - "Embrapa Instrumentação Agropecuária", Documentos 15, versão eletrônica (ISSN 1518-7179), São Carlos (2005).

9. Leandro, R. C. \& Yuyama, K. - Acta Amazôn., 38, p.597 (2008). http:// dx.doi.org/10.1590/S0044-59672008000400001
10. Razera, I. A. T. - "Fibras lignocelulósicas como agente de reforço de compósitos de matriz fenólica e lignofenólica", Dissertação de Mestrado, Universidade de São Paulo, Brasil (2006).

11. Joshi, S. V.; Drzal, L. T.; Mohanty, A. K. \& Arora, S. - Compos. Part A, Appl. Sci. Manuf., 35, p.371 (2004). htp://dx.doi.org/10.1016/j. compositesa.2003.09.016

12. Fávaro, S. L; Lopes, F. O. \& Radovanovic, E. - "Preparação de compósitos de polietileno pós- consumo com Fibras de sisal e estudo de suas propriedades físico-químicas e Morfológicas", in: Anais do $17^{\circ}$ Congresso Brasileiro de Engenharia e Ciência dos Materiais, Foz do Iguaçu, PR, Brasil (2006).

13. Fengel, D. \& Wegener, G. - "Wood, chemistry, ultrastructure, reactions". Walter de Gruyter, Berlim, p.613 (1989).

14. Van Soest, P. J. - "Nutritional Ecology of the Ruminant", 2.ed. Ithaca, Cornell University Press, New York (1994).

15. Masson, J.-F. \& Bundalo-Perc, S. - Thermochim. Acta, 436, p.35-42 (2005). http://dx.doi.org/10.1016/j.tca.2005.06.025

16. Isacsson, U. \& Lu, X. - Fuel, 76, p.1353-359 (1997). http://dx.doi. org/10.1016/S0016-2361(97)00144-0

17. Wen, G.; Zhang, Y.; Sun, K. \& Fan, Y. - Polymer Testing, 21, p.295-302 (2002). http://dx.doi.org/10.1016/S0142-9418(01)00086-1

18. Castro, J. C.; Figliuolo, R.; Nunomura, S. M.; Silva, L. P.; Mendes, N. B.; Costa, M. S. T.; Barreto, A. C.; Cunha, T. M. F. \& Koolen, H. H. F. - "Produção Sustentável de Biodiesel a partir de oleaginosas amazônicas em comunidades isoladas”, in: Resumos do I Congresso da Rede Brasileira de Tecnologia de Biodiesel. Brasília, Brasil, (2006).

19. Chen, Z.; Wu, S.; Zhu, Z.; \& Liu, J. - J. Cent. South Univ. Technol. 15, p.135-139 (2008). http://dx.doi.org/10.1007/s11771-008-0332-0

20. Fagury, R. V. G. - "Avaliação de fibras naturais para a fabricação de compósitos: açaí, coco e juta”, Dissertação de Mestrado, Universidade Federal do Pará, Brasil (2005).

21. Carrijo, O. A.; Liz, R. S. \& Makishima, N. - Hortic. Bras. 20, p.533-535 (2002). http://dx.doi.org/10.1590/S0102-05362002000400003

22. Martin, A. R.; Martins, M. A.; Mattoso, L. H. C. \& Silva, O. R. R. F. - Polímeros, 19, p.40 (2009).

23. Badadopulos, L. F. A. L.; Vale, A. C.; Soares, J. B. \& Casagrande, M. D. T. - "Estudo laboratorial da viabilidade do uso de fibras sintéticas em misturas do tipo SMA". in: Resumos da $15^{\text {a }}$ Reunião de Pavimentação urbana. Salvador, Brasil (2008).

24. Wu, S.; Chen, Z. \& Ye, Q. - J. Wuhan Univ. Technol., 21, p.118-120 (2006).

25. Mothé. M.G. - "Estudo do Comportamento de ligantes asfálticos por reologia e análise térmica", Dissertação de Mestrado, Universidade Federal do Rio de Janeiro, Brasil, (2009).

26. American Society for Testing and Materials - ASTM. - "ASTM D2872: Standard Test Method for Effect of Heat and Air on a Moving Film of Asphalt (Rolling Thin-Film Oven Test)", Philadelphia (2004).

27. American Society for Testing and Materials - ASTM. - "ASTM D5: Standard Test Method for Penetration of Bituminous Materials", Philadelphia (2006).

28. American Society for Testing and Materials - ASTM. - "ASTM D36: Standard Test Method for Softening Point of Bitumen (Ring-and-Ball Apparatus)", Philadelphia (2010).

29. American Society for Testing and Materials - ASTM. - "ASTM D113: Standard Test Method for Ductility of Bituminous Materials", Philadelphia (2007).

30. American Society for Testing and Materials - ASTM. - "ASTM D70: Standard Test Method for Density of Semi-Solid Bituminous Materials (Pycnometer Method)", Philadelphia (2009).

31. American Society for Testing and Materials - ASTM. - "ASTM D4402: Standard Test Method for Viscosity Determination of Asphalt 
at Elevated Temperatures Using a Rotational Viscometer", Philadelphia (2006).

32. American Society for Testing and Materials - ASTM. - "ASTM E102: Standard Test Method for Saybolt Furol Viscosity of Bituminous Materials at High Temperatures", Philadelphia (2003).

33. American Society for Testing and Materials - ASTM. - "ASTM D92: Standard Test Method for Flash and Fire Points by Cleveland Open Cup Tester", Philadelphia (2005).

34. American Society for Testing and Materials - ASTM. - "ASTM D2042: Standard Test Method for Solubility of Asphalt Materials in Trichloroethylene", Philadelphia (2009).

35. Lima, C. K. M. - "Estudo da incorporação de resíduo industrial polimérico ao CAP”. Dissertação de Mestrado, Universidade Federal do Rio Grande do Norte, Brasil (2008).

36. Oda, S. - "Análise da Viabilidade Técnica da Utilização do Ligante Asfalto - Borracha em Obras de Pavimentação", Tese de Doutorado, Universidade de São Paulo, Brasil (2000).
37. Brasil. Departamento Nacional de Infraestrutura de Transportes - DNIT. - "Pesquisa de Asfaltos Modificados por Polímeros. Departamento Nacional de Estradas e Rodagem". Relatório Final. Ministério dos Transportes, Diretoria de Desenvolvimento Tecnológico. Tomo I e II (1998).

38. Lanchas, S. - "Características del Stone Mastic Asphalt SMA”, in: Anais do Congreso Ibero Latinoamericano del Asfalto - $10^{\circ}$ CILA, v.01, p.727-730, Sevilha, Espanha (1999).

39. Horst, E. - "Stone Mastic Asphalt - Pavement Technology”, in: Anais do $15^{\circ}$ Encontro de Asfalto - IBP 62000, p.143-151, Rio de Janeiro, Brasil (2000).

40. Canevarolo Junior, S. V. - "Técnicas de caracterização de polímeros", 2.ed., Artliber, São Paulo (2004).

Enviado: $11 / 12 / 10$

Reenviado: 17/09/11

Aceito: 03/11/11 